\title{
Ações das equipes volantes de CRAS no interior do Rio Grande do Norte
}

Marília Noronha Costa do Nascimento. Serviço de Proteção ao Adolescente em Cumprimento de Medidas Socioeducativas em Meio Aberto da Cidade de Natal/RN.

Isabel Fernandes de Oliveira. Universidade Federal do Rio Grande do Norte.

\section{Resumo}

As equipes volantes de CRAS surgiram para viabilizar o acesso das famílias que vivem em regiões de difícil acesso ou grande espalhamento territorial aos serviços socioassistenciais. Investigou-se como as ações dessas equipes respondem às demandas de seus territórios no Rio Grande do Norte. Foram realizadas oito entrevistas semiestruturadas com equipes de sete municípios. Devido à falta de infraestrutura e quantidade de comunidades rurais espalhadas pelos territórios, a presença das equipes nas áreas rurais se torna esporádica, fragilizando a continuidade das ações. O conhecimento das profissionais sobre a realidade dos territórios é precário, pois a busca pelas demandas é assistemática. Entretanto, algumas equipes realizam ações que buscam romper com os limites e práticas assistencialistas, promovendo articulações com equipamentos e movimentos sociais que estão mais próximos às famílias.

Palavras-chave: política social; intervenções psicossociais; ambientes rurais; áreas de pobreza.

\begin{abstract}
CRAS mobile teams' performance in the countryside of Rio Grande do Norte. The CRAS mobile teams were created to enable the access of families who live in areas which are difficult to access or have an extensive territory to the social services. We investigated how the performance of these mobile teams meets the demands of their territories in Rio Grande do Norte by making eight semi-structured interviews with teams that work in seven small towns. Given the lack of infrastructure and the number of rural communities scattered throughout the territory, the presence of the teams in rural areas becomes sporadic and ultimately the continuity of actions is undermined. The knowledge of the professionals about the reality of the territories is precarious, as the search for demands is asystematic. Nevertheless, some teams perform strategies and actions that seek to overcome the limits and the traditional assistencialism, working in partnership with social movements and equipments that are closer to the families.
\end{abstract}

Keywords: social policy; psychosocial interventions; rural settings; poverty areas.

\section{Resumen}

Acciones de los equipos móviles de CRAS dentro del Rio Grande do Norte. Los equipos móviles del CRAS han surgido para facilitar el acceso de las familias que viven en zonas de difícil acceso o gran dispersión territorial para los servicios de asistencia social. Se investigó como las acciones de estos equipos responden a las demandas de sus territorios en el Rio Grande do Norte. Se realizaron ocho entrevistas semi-estructuradas con equipos de siete municipios. Debido a la falta de infraestructura y cantidad de comunidades rurales dispersadas por los territorios, la presencia de los equipos en las zonas rurales se vuelve esporádica, lo que debilita la continuidad de las acciones. El conocimiento de los profesionales sobre la realidad de los territorios es precaria, ya que la búsqueda de las demandas es poco sistemática. Sin embargo, algunos equipos realizan acciones que buscan romper con los límites y prácticas tradicionales, promoviendo las conexiones con los materiales y movimientos sociales que están más cerca de las familias.

Palabras-clave: politica social; intervenciones psicosociales; medio rural; zonas de pobreza. 
Dada a crescente implantação dos Centros de Referência de Assistência Social (CRAS) em todo o território nacional e a consequente ampliação da inserção de profissionais nesse campo (Macedo et al., 2011), muitos estudos foram realizados acerca das ações desenvolvidas nesses e em outros estabelecimentos da política de Assistência Social (Botarelli, 2008; Dantas, 2013; I. F. Oliveira, Dantas, Solon, \& Amorim, 2011; Romano, 2009; Senra \& Guzzo, 2012; Ximenes, Paula, \& Barros, 2009). Esta pesquisa está situada nesse campo, mas contempla nuanças que tratam do processo de interiorização do trabalho do psicólogo realizado nas equipes volantes de CRAS, associado ao desenvolvimento de uma política pública cujo foco está, nesse caso, dirigido a uma população que historicamente tem acessado de forma muito incipiente qualquer proteção do Estado. Além disso, tal população possui características que põem em xeque os elementos normatizadores que caracterizam as políticas sociais brasileiras, essas marcadamente focalizadas e que, no cenário neoliberal atual, encontram-se num maior tensionamento entre o papel protetor do Estado e sua desresponsabilização pela pobreza que seu suporte à dinamiza capitalista gera.

As equipes volantes estão em expansão por meio do Plano Brasil Sem Miséria (Paes-Sousa, 2013). Esse Plano foi implementado no governo Dilma Rousseff, como continuidade à políticas de combate à pobreza mais focalizadas e tem como objetivo promover a inclusão social e produtiva da população extremamente pobre, tornando residual o percentual dos que vivem abaixo da linha da extrema pobreza. A Assistência Social é incorporada ao mesmo como um dos eixos de execução de 'acesso aos serviços'. Nessa esteira, as equipes volantes do CRAS visam viabilizar o acesso das famílias que vivem em regiões de difícil acesso ou grande espalhamento territorial às políticas de combate à pobreza. Em contextos em que o território possui grande extensão, difícil acesso e/ou presença de populações tradicionais (comunidades indígenas, quilombolas, ribeirinhas) equipes volantes são implementadas para compor a equipe dos CRAS dessas regiões (Ministério do Desenvolvimento Social e Combate à Fome [MDS], 2011).

Segundo o MDS (2011), as equipes volantes não são equipes extras, nem isoladas. Elas fazem parte do conjunto de trabalhadores do CRAS e devem estar integradas a ele. Apesar de manterem vínculo com o CRAS ao qual pertencem, têm como característica essencial o deslocamento ao longo do território para a oferta de serviços da proteção social básica a essas famílias. Para isso, a principal estratégia utilizada deve ser a busca ativa, que é uma maneira de se fazer presente no território e manter a proximidade com os usuários, e não apenas esperar demandas espontâneas da população. Logo, faz-se necessário um trabalho que considere o contexto sociocultural no qual se inserem.

Então, para que essas equipes respondam às expectativas das regiões habitadas por essas populações específicas, é imperioso que os profissionais façam uso do território, que estejam imersos no dia-a-dia, na história e no universo cultural dos moradores, conheçam seus hábitos e os fatos que influenciam suas vidas, pois, segundo Milton Santos (2000), a análise do território não se separa da dos sujeitos que dele se utilizam.

No RN, tais equipes estão presentes em alguns municípios pequenos do interior, que vivenciam contextos de pobreza, em especial uma pobreza que se abriga no meio rural. A realidade rural com a qual as equipes investigadas lidam no cotidiano de trabalho possui singularidades marcantes do interior nordestino e norte-rio-grandense, cujas características precisam ser apresentadas num esforço de compreender o território em sua totalidade.

De acordo com o Instituto Nacional do Semiárido (2012), o estado do Rio Grande do Norte se destaca por possuir $92,97 \%$ do seu território e apresentar $88,02 \%$ de seus municípios na porção semiárida, estando acima do percentual do Nordeste, que apresenta $56,46 \%$ do território e 58,53\% de seus municípios nessa região.

Esses dados revelam que o Estado sofre periodicamente com a falta de chuva, acirrando os problemas sociais no decorrer de sua história, sobretudo no interior. Mas a seca no estado é mais que um fenômeno estritamente climático: ela está associada ao modelo de desenvolvimento da agricultura no Nordeste, cuja histórica concentração de terra e de água provoca graves sofrimentos aos pequenos produtores que tiram o sustento desses recursos (Andrade, 1981; I. M. Oliveira, 2005).

Ainda que o fenômeno climático da seca imponha dificuldades, a pobreza que marca a região foi produzida e reproduzida com base em sua estrutura política e econômica. A concentração de terra e riqueza também se transformou em concentração de poder nas mãos das oligarquias, que historicamente se apropriaram dos recursos voltados para o combate à seca e para o desenvolvimento regional como meio de se manterem no poder, promovendo um projeto de modernização parcial e excludente (Furtado, 1980). 
A partir de dados do IPEA sobre o Índice de Desenvolvimento Humano (IDH) e o Coeficiente de Gini do estado, Dantas (2013) mostra que o RN vem apresentando melhoras nos indicadores sociais, sendo destaque no Nordeste, principalmente em relação às taxas de pobreza. Contudo, segundo a autora, não se pode perder de vista que a região nordestina possui um dos mais altos índices nacionais de pobreza e desigualdade e que, portanto, o RN ainda está entre os estados mais pobres e desiguais do Brasil. Além disso, a despeito dos números das pesquisas, os problemas sociais existentes não perdem sua gravidade; muito menos a necessidade de combatê-los diminui.

Sobre a pobreza extrema rural, Buainain e Júnior (2013) mostram que ela está fortemente concentrada no semiárido brasileiro (onde o interior do RN está localizado) e que existe um grande número de ações e programas instituídos para enfrentá-la. Contudo, revelam um panorama de fragmentação dessas estratégias, que acontecem de forma isolada, sem condições de mudar a realidade do beneficiário. Segundo os autores, isso é resultado de uma visão que não considera a pobreza em sua multidimensionalidade.

Nesse contexto, as equipes volantes emergem como uma estratégia vinculada à principal política de combate à pobreza, dentro do Plano Brasil Sem Miséria. Associando o trabalho das equipes volantes e o contexto do combate à pobreza em regiões rurais do nordeste brasileiro, questiona-se: como tem sido esse trabalho? Quais as suas bases? Quem se envolve? As demandas para as equipes volantes diferem daquelas que chegam aos equipamentos físicos dos CRAS? Mesmo fazendo parte do mesmo serviço, há diferenças entre o trabalho das equipes volantes e do CRAS? Quais as dificuldades? Tendo essas questões como horizonte de investigação, o objetivo da pesquisa foi investigar como as ações das equipes volantes de CRAS respondem às demandas de seus territórios de abrangência no Rio Grande do Norte. A seguir, esclarecemos os caminhos dessa investigação.

\section{Método}

Inicialmente foi realizado um mapeamento dos CRAS do RN que possuíam equipes volantes e foram levantadas informações cadastrais e gerenciais de cada unidade por meio de consulta ao Sistema de Cadastro do SUAS (CadSUAS). Segundo a Secretaria de Estado do Trabalho, da Habitação e da Assistência Social (SETHAS), no período da coleta de dados, havia 10 equipes volantes distribuídas em nove municípios do estado, pois um deles possuía duas equipes.

A partir da consulta ao CadSUAS, foi possível acessar as informações de todos os CRAS aos quais essas equipes estavam vinculadas e, em seguida, contatar por telefone as profissionais ${ }^{1}$ para convidá-las a participar da pesquisa. Duas equipes foram excluídas do estudo, uma delas porque a equipe estava parada há algum tempo e sem perspectivas de voltar a funcionar, por razão de instabilidade política no município; e a outra pela impossibilidade de as profissionais participarem da entrevista por motivos pessoais.

A investigação foi realizada por meio de entrevistas semiestruturadas com as profissionais de cada uma das oito equipes restantes, a partir de um roteiro que continha temas norteadores agrupados em blocos de questões que orientaram esta pesquisa. Os temas giraram em torno da formação para o trabalho na Assistência Social, atividades realizadas, redes de cooperação e trabalho, desafios da política, dificuldades para a realização do trabalho, demanda e características do público atendido. A maioria das entrevistas aconteceu em equipe (duas profissionais), com exceção de duas, pois havia equipes volantes que não possuíam o quadro completo de profissionais. Com o consentimento das participantes, as entrevistas foram registradas em áudio e posteriormente transcritas na íntegra para análise.

Os dados das entrevistas foram organizados e agrupados, tendo como eixo inicial as categorias do instrumento, que foram adaptadas, agrupadas e reorganizadas, a partir da leitura do material e da análise qualitativa de seu conteúdo textual. Entretanto, outras categorias emergiram a partir da leitura e análise das entrevistas, assim como algumas constantes no roteiro não se mantiveram enquanto tal. As análises, a partir de temáticas identificadas após a leitura e a apropriação do conteúdo das entrevistas, foram conduzidas de modo a compreender o fenômeno sem perder de vista as determinações do contexto histórico-social no qual ele se processa.

\section{Resultados e discussão}

\section{Caracterização das Equipes Volantes}

Do total de equipes entrevistadas (oito), havia seis com duas profissionais de nível superior, já as outras duas contavam apenas com uma. Das equipes que tinham o quadro completo de profissionais, cinco 
eram compostas por uma assistente social e uma psicóloga, e apenas uma equipe era formada por uma assistente social e uma psicopedagoga. Já as duas equipes com o quadro incompleto contavam apenas com uma assistente social cada. Essas duas, na verdade, nem poderiam ser chamadas de equipes, já que possuem apenas um profissional.

No que se refere à data de implantação das equipes volantes no estado, metade das entrevistadas (quatro) estava atuando há pouco mais de um ano e meio em seus municípios. Apenas duas já trabalhavam há mais de dois anos. As outras duas estavam funcionando há menos de um ano.

A recenticidade na implementação das equipes justifica a precariedade e a fase inicial de certas ações. A novidade também se constata no cenário nacional, pois, apesar de já estarem previstas na tipificação dos serviços socioassistenciais (MDS, 2009a), apenas após o ano de 2011, com o lançamento do Plano Brasil Sem Miséria, as equipes volantes começaram a se expandir pelo território nacional.

Diante da imensidão do território e da quantidade de comunidades que se encontram dispersas, as quais a equipe volante precisa cobrir - sem falar nas dificuldades de acesso e falta de infraestrutura -, é praticamente inviável dar conta de todo o trabalho que necessita ser realizado, mesmo com a equipe completa. Então, as equipes que não estavam com o quadro completo de profissionais se articulavam com a equipe fixa do CRAS para conseguir dar continuidade ao trabalho. Assim, recebiam ajuda para realizar as ações nas comunidades rurais e, por sua vez, auxiliavam nas atividades da equipe fixa.

De acordo com o MDS (2011), as equipes volantes não são equipes extras, nem isoladas. Elas compõem o conjunto dos trabalhadores do CRAS e devem estar integradas. Contudo, se por um lado a estratégia de ajuda mútua para dar conta do trabalho é imprescindível e importante para que os serviços não fiquem parados e para que se possam estabelecer fluxos entre eles, por outro, as profissionais acabam se submetendo a uma carga de atividades extras por não receberem as condições de infraestrutura necessárias ao desenvolvimento das ações, a exemplo do transporte para acessar as áreas rurais.

Uma das ferramentas mais básicas para que as equipes volantes realizem um trabalho contínuo nas zonas rurais é o transporte, pois têm que se deslocar pelo território, cuja extensão é grande e cujas comunidades estão espraiadas. Sem o deslocamento não há como a oferta de serviço socioassistencial chegar às comunidades rurais. E um dos principais desafios dessas equipes começa antes de entrarem em contato com os usuários, visto que a maioria não possui carro exclusivo para o serviço e, quando possui, faltam recursos para gasolina ou têm de dividi-lo com outras secretarias.

A falta do carro para as equipes volantes se torna emblemático porque acentua ainda mais a contradição de uma política que enfrenta dificuldade em garantir até as condições de infraestrutura mais básicas para que seus programas, serviços e projetos se realizem. Essas equipes foram idealizadas para garantir que os serviços socioassistenciais chegassem àqueles usuários que tinham cerceamento ao acesso, mas as próprias profissionais esbarram nos limites do acesso às comunidades rurais e têm seu trabalho prejudicado.

A precariedade encontrada nos serviços da Assistência Social é marca histórica de uma política social pouco valorizada, que no cotidiano se torna ineficiente, ainda que garanta alguns direitos. Apesar dos avanços legais nesse campo, a operacionalização das conquistas se dá a passos lentos e, muitas vezes, em discordância com a proposta política original, porque se opõem ao ideário neoliberal, que reconhece a necessidade de ajudar os pobres, mas não de concretizar os seus direitos (Couto, Yazbek, \& Raichelis, 2011).

Ainda é oportuno destacar que esse cenário das condições de trabalho se agrava mais em cidades pequenas, que geralmente possuem estruturas administrativas frágeis e dependem financeiramente dos governos estadual e federal (Raichelis, 2011). As transferências do governo federal exigem, cada vez mais, a contrapartida dos municípios, uma vez que radicaliza a descentralização. Essa contrapartida se dá, basicamente, com relação à contratação de profissionais e infraestrutura. O MDS transfere aos municípios valores que servem para a execução de ações, mas, na verdade, os gestores municipais usam essa verba para pagamento de pessoal e pouco ou nada sobra para as ações. Essa é a realidade das equipes volantes no RN, cuja falta de condições materiais de trabalho torna incerto o contato com as populações rurais e prejudica as ações mais elementares.

\section{Território de Atuação e Particularidades do Trabalho na Zona Rural}

É com o cenário da pobreza rural que as equipes volantes se deparam no cotidiano de trabalho. No RN, 
elas estão situadas em cinco microrregiões das 19 existentes no estado e estão entre as cinco microrregiões com o maior índice de pobreza extrema rural, segundo dados do Censo de $2010^{2}$, realizado pelo IBGE. Ou seja, metade dessas equipes atua nas regiões mais pobres do estado.

Segundo as profissionais, são territórios muito extensos e de difícil acesso, onde há comunidades, assentamentos e sítios bastante espalhados. As falas a seguir elucidam a abrangência dos territórios: "porque quando eu digo que tem quatro áreas não significa dizer que são quatro sítios, mas uma área que envolve no mínimo de 18 a 20 sítios, que ficam muito distantes um do outro" (Equipe03). "São três distritos, além do município de [nome do município], e 300 sítios e comunidades. Nesses dois anos, eu ainda não conheço alguns" (Equipe06).

Os trechos acima sobre o tamanho dos territórios constituem mais um exemplo que expõe a contradição da política: a inviabilidade de sua plena efetivação diante do que ela mesma preconiza - definição das ações dos serviços, número de famílias a serem atendidas, extensão do território de abrangência e quantidade de profissionais por equipes -, pois é incompativel com as condições de trabalho que são oferecidas, ainda que os serviços funcionem em ótimo nível, com a equipe completa e a infraestrutura que é recomendada.

No geral, as equipes descreveram alguns elementos importantes para a compreensão dos territórios nos quais atuam. Contudo, chama a atenção o fato de darem mais destaque aos aspectos negativos do território, possivelmente porque a forma como as ações estão preconizadas não atende às particularidades do território nacional. Se aqui se chama a atenção para o território de seca, de uma população que historicamente não teve suas potencialidades desenvolvidas, especialmente porque no nordeste brasileiro a marca do coronelismo impera, assim como o voto de cabresto, o trabalho análogo ao escravo, e o domínio das pequenas cidades pelas grandes famílias senhoras de terra, em outras regiões, como apontado por Belo (2015), chama atenção as especificidades indígenas, ribeirinha, de regiões de rio, cuja dimensão temporal adquire outra perspectiva e diante da qual o trabalho da assistência necessita ser redimensionado.

Durante as entrevistas, muita ênfase foi dada à característica climática da região, comum a todas elas. Ao discorrerem acerca dos amplos períodos de seca que assolam grande parte do interior do $\mathrm{RN}$, geralmente complementavam contando das consequências para a população que, em sua maioria, vive da agricultura e criação de gado; outras famílias vivem apenas com o auxílio dos benefícios socioassistenciais, a exemplo do Programa Bolsa Família (PBF), do Benefício de Prestação Continuada (BPC), e da aposentadoria. Assim, também destacaram a pobreza extrema como aspecto marcante do território. "Muita seca, e isso faz com que as questões sociais se acirrem ainda mais. Você sabe que a seca é um fator importante, principalmente numa cidade que a base da economia é a agricultura" (Equipe08).

Ainda sobre as dificuldades que essas populações enfrentam em virtude dos tempos de seca, a fala de uma profissional chamou muita atenção:

Sabe o que eu sinto, também? Que a zona rural vai se acabar, tá se acabando. Eles não querem ficar mais na zona rural. Devido às dificuldades, que não... Não existe mais chuva, então, vão ficar ali fazendo o quê? Se a sobrevivência deles é o quê? A terra, né, plantar para colher, é o gado. Então, não tem... Tá se acabando mesmo a zona rural. Eu sinto isso. (Equipe01)

De fato, muitas famílias migram da zona rural para a cidade em busca de sobrevivência e melhores condições de vida, ainda que esse acontecimento não seja recente e tenha mudado ao logo dos anos. Contudo, a seca e suas sequelas não são fenômenos naturais. É preciso compreendê-las em sua totalidade, sem separá-las do processo de constituição e estruturação das sociedades brasileira, nordestina e norte-rio-grandense, que carregam em sua história as marcas da concentração fundiária, dos poderes oligárquicos, do coronelismo e assistencialismo (Andrade, 1981; I. M. Oliveira, 2005; Spinelli, 2010).

O irrisório planejamento e investimento do Estado para minimizar os impactos da estiagem na vida da população mais pobre faz com que as famílias fiquem à mercê dos dias de chuva. O trecho a seguir é exemplo da desigualdade e pobreza existentes mesmo em áreas de terras férteis, pois estão relacionadas ao padrão de desenvolvimento da agricultura no Nordeste e à histórica concentração de terra na região, que excluem os pequenos agricultores (Andrade, 1981); bem como à omissão do Estado, que não garante o acesso à água de forma igual para todos.

Não sei se você sabe, mas tem uma pesquisa que a [nome da região/omitida para não identificar o profissional] é uma das regiões mais férteis do planeta. Então, tudo o que plantar aqui, dá. Como os

Estudos de Psicologia, 23(2), abril a junho de 2018, 122-132 
japoneses que têm uma plantação de melão aqui em cima. Mas eles têm irrigado, né? Só que aqui não existe projeto para essas comunidades. (Equipe02)

Quando elas não conseguem tirar o sustento da própria produção - já que dependem da chuva para molhar a terra, pois os projetos de irrigação não são voltados para o pequeno agricultor, mas para as agroindústrias -, precisam trabalhar para terceiros, muitas vezes se submetendo a condições bastante degradantes. Então, são famílias que vivem num cenário de exploração, vulnerabilidade e pobreza, como os descritos pela Equipe02:

Como eles são agricultores, a maioria não tem outro meio de vida, de sobrevivência, dependem disso. Aí muitos, quando estava no período da seca, o que faziam? Eles trabalhavam nas pedras da [nome da região/omitida para não identificar o profissional]. Na Caieira. Em outras palavras, o lugar onde faz Cal. Quebrar pedra. É um trabalho bastante desumano. $\mathrm{E}$, assim, trabalha muito para ganhar muito pouco. Então, assim, é um trabalho de exploração.

São casas ainda de taipa, que não têm acesso à água, muitas comunidades já têm pelo menos os poços, mas muitas andam quilômetros para conseguir água, e água muito ruim, barrenta. Casas de taipa com condições mínimas de sobrevivência, porque não têm banheiro. Então, as condições sociais, realmente, são essas. Muito triste. Tudo seco, os animais morrendo.

O trabalho na assistência demanda o combate diário à pobreza, mas também a todas as outras sequelas que dela derivam. O Programa Brasil sem Miséria tinha como eixos algumas iniciativas que visavam a minimização dos problemas causados pela seca no Nordeste. A construção de poços e cisternas, programas de inclusão produtiva e de acesso ao trabalho (ACESSUAS) buscavam ampliar e configurar uma rede de combate à pobreza atuando em diferentes esferas. Esse programa perdeu muito de sua força após o impeachment da presidente, restando ações reduzidas do ACESSUAS. Para os psicólogos, os entraves e problemas que os profissionais enfrentam para atuar nessa direção são inúmeros, passam pelos limites da ciência e formação profissional e muito pela natureza e configuração da política social, que não tem como alvo a supressão da pobreza. É possível perceber que os programas de transferência de renda nos governos Lula e Dilma mudaram as condições de vida de milhões de famílias no Brasil, principalmente no Norte e Nordeste assim como a redução nos níveis de pobreza, a elevação do poder de compra dos salários e a ênfase no foco resgate e exercício dos direitos sociais (Yamamoto \& Oliveira, 2010). Entretanto, essa linha de condução dos gastos sociais juntamente com um pesado investimento na economia, denominada por alguns analistas de "neodesenvolvimentista", não foi capaz de consolidar um estado de Bem-Estar Social, que efetivamente garantisse direitos sociais de mais largo curso. Tanto essa afirmação é verdadeira que menos de dois anos depois do golpe de destituiu a presidente, vários projetos que privilegiavam os mais pobres foram excluídos, tiveram redução drástica de financiamento ou foram absorvidos por parcerias público/privadas como é o caso da assistência social com o Programa Criança Feliz, receptor de $80 \%$ do financiamento dessa política.

Quando perguntadas sobre as peculiaridades do meio rural, parte das equipes elencou alguns aspectos culturais das comunidades e das famílias, cujas especificidades marcavam o cotidiano de trabalho e exigiam o repensar de suas ações. Dentre as características, duas equipes citaram o "dialeto diferente" de algumas comunidades, que requer das profissionais o cuidado para compreenderem e serem compreendidas pelas pessoas, de forma a melhor atendê-las e alcançar os objetivos das ações.

Outra particularidade se referia aos costumes diários dos moradores das zonas rurais, que possuem rotina diferente da dos que vivem na cidade, demandando da equipe uma adequação do trabalho à realidade da população rural. Para Koga e Nakano (2005), "atender às demandas dessas populações exigem respostas adequadas às peculiaridades desse mundo rural diversificado e suas expectativas, que podem ter contornos diferentes daqueles pensados para o mundo urbano." (p. 7). Então, é preciso que as equipes atentem para o fato de que cada lugar possui uma dinâmica própria e, por isso, é preciso que estejam vigilantes em relação às singularidades e à história de cada comunidade a fim de responder de modo apropriado e eficaz a suas necessidades e demandas.

Já a equipe que tinha em seu território de abrangência a presença de quilombolas focou apenas na dificuldade que tinha de trabalhar com os usuários da comunidade. De acordo com as profissionais, eles eram bastante reservados e interagiam pouco. A referência que as profissionais fizeram à comunidade quilombola não incluía componentes históricos e culturais que fazem parte da identidade dessa população específica. 
Reconhecer tais características é indispensável para se pensar em intervenções voltadas à garantia de direitos dessas famílias, necessários a sua sustentabilidade e existência enquanto grupo étnico, e constitui uma das principais funções das equipes volantes.

As peculiaridades das populações tradicionais já vêm sendo preocupação das entidades de representação da Psicologia, com destaque para o Conselho Federal de Psicologia. Reflexo de movimentos sociais mais amplos em defesa das minorias, a categoria tem assumido bandeiras importantes nessa direção, realizando estudos e formalizando direções para o trabalho dos profissionais com públicos diversificados. Ainda são iniciativas preliminares, mas as discussões estão bastante aquecidas.

Outras equipes também falaram da dificuldade em estimular os usuários a participar das ações promovidas por elas. No entanto, as profissionais atribuíram essa limitação a características particulares das pessoas que vivem na zona rural, julgando-as como tímidas e/ou acomodadas: "A dificuldade que eu sinto é de eles realmente participarem. O pessoal da cidade, eles participam mais, eles têm mais vontade de aprender. $\mathrm{E}$ os da zona rural são mais acomodados." (Equipe01).

Sem se darem conta de que é preciso, inicialmente, conhecer a dinâmica do cotidiano das famílias, suas dificuldades, prioridades, potencialidades e demandas, bem como tornar a equipe conhecida para que possam ofertar um serviço coerente e significativo para a população, as equipes não conseguem conquistar a participação e interesse das pessoas e acabam culpabilizando-as, sem questionarem a própria prática e o distanciamento dela em relação a realidade dos usuários. O Centro de Referências Técnicas em Psicologia e Políticas Públicas (CREPOP) do Conselho Federal de Psicologia tem propiciado vários espaços de investigação e discussão sobre a atuação do psicólogo nas políticas públicas, assim como a Comissão Nacional de Psicologia na Assistência Social (CONPAS/CFP). Nas suas avaliações, ainda há uma grande discrepância entre as demandas do campo de trabalho e o retorno que os psicólogos vêm dando por meio de suas atividades. Sem dúvida muito já se avançou na Assistência Social, mas também existe uma luta diária contra posições tutelares, conservadoras, que psicologizam a questão social e subjetivizam as sequelas da pobreza. Essa dinâmica é contínua e esses espaços têm constituído fontes de resistência importante seja frente ao desmonte das políticas públicas, seja como proposta ao fortalecimento do trabalho do psicólogo sob a égide de um projeto comprometido com a classe trabalhadora.

As equipes ainda apontaram como aspecto marcante da população rural a falta de conhecimento em relação aos direitos, que está fortemente relacionada à histórica cultura do favor que persiste na região.

Eles agradecem como se a gente estivesse fazendo um favor, e a gente... Até compreenderem que de fato é um direito deles e que a gente está indo trabaIhar e não fazer assistencialismo. É interessante porque isso é bem mais forte na zona rural. (Equipe08)

Dantas (2013) lembra que há nas cidades pequenas a presença forte de uma política partidária local, que marca a gestão dos serviços com uma lógica conservadora e clientelista, especialmente na Assistência Social. Embora as profissionais entrevistadas, que estão na ponta do serviço, não reproduzam essa lógica em suas ações - pelo contrário, buscam desconstruí-la por meio de orientações à população -, os próprios usuários acabam vinculando os serviços socioassistenciais às ações clientelistas, enxergando-os como favor, e não direito; associando-os às práticas de grupos políticos tradicionais que fazem uso privado e eleitoreiro dos programas e serviços da política de Assistência Social.

A questão política lá é muito forte. Então, se a gente vai desenvolver um trabalho para a comunidade, e por ser a secretaria que está levando, por ser um profissional que está trabalhando na gestão $\mathrm{A}$ ou $\mathrm{B}$, eles não participam porque acham que é "fulaninho" quem está mudando. Lá ainda tem muito esse ideário político de "eu não vou participar porque não foi tal candidato que fez". (Equipe03)

Em relação à estrutura física para realizar o trabaIho, as equipes volantes contam com os espaços públicos existentes em cada sítio, assentamento ou comunidade quando necessitam de um ambiente maior para realizar as ações, a exemplo das de caráter mais coletivo. Como são muitas comunidades, torna-se inviável ter uma sede própria da equipe em cada lugar. Então, elas fazem parceria com os gestores da educação, líderes religiosos e comunitários e agentes comunitários de saúde para que as ações ocorram nas escolas, igrejas, associações comunitárias ou UBS.

Realizar as intervenções nos equipamentos da comunidade é um meio de a equipe construir uma noção do território ao utilizá-lo, fazer parte do cotidiano da população e, assim, poder conhecer de perto as vulnerabilidades e vislumbrar as potencialidades, que 
podem ser descobertas nesses mesmos ambientes. Por exemplo, ao proporcionar a aproximação das profissionais das equipes volantes com os da saúde, educação e com os líderes das comunidades, suscita a articulação de ações entre os serviços e a troca de informações acerca daquela realidade, potencializando o trabalho.

\section{Ações das Equipes Volantes em Territórios Rurais do $R N$}

Para que a equipe volante contemple o que as comunidades precisam, é essencial que os profissionais conheçam fatos que influenciam o modo de vida das pessoas. Então, a primeira ação a ser realizada deveria ser a busca ativa. Nesse sentido, uma das equipes manifestou a importância de ir buscar no território elementos que contribuam para uma atuação mais próxima da realidade dos usuários.

É diferente de você estar dentro de uma unidade, desenvolvendo um grupo, e chegar Maria e dizer: "minha casa está quase caindo". E eu posso imaginar como seria a casa dela. A casa dela é quase caindo. Mas quando eu chego lá, na casa dela, e eu vejo o estado da casa, é diferente. (Equipe03)

A busca ativa já estava preconizada para o trabalho dos CRAS, de acordo com o guia "Orientações Técnicas: Centro de Referência de Assistência Social CRAS" (MDS, 2009b), mas foi retomada pelo Plano Brasil Sem Miséria como principal estratégia das equipes volantes. Ela envolve atividades de divulgação do serviço, contato com atores sociais locais, circulação da equipe pelo território e obtenção de informações de outros serviços socioassistenciais e setoriais. Ela integra diversas ações e é base para o planejamento de todas as outras.

Durante as entrevistas, metade das equipes (quatro) citou o termo "busca ativa", referindo-se ao ato de identificar as demandas no próprio território. No entanto, ao analisar as descrições das ações realizadas pelas profissionais, verificou-se que todas elas promovem pelo menos uma ação de busca ativa nas áreas rurais em que atuam. Dentre as atividades que compõem a estratégia, são realizadas divulgação do serviço; contato com atores sociais locais e compartilhamento de informações com técnicos do PBF, profissionais da saúde e da educação.

A atividade de divulgação do serviço é de extrema importância, pois é por meio dela que os usuários começam a conhecer melhor as funções e os objetivos das equipes volantes, saber da existência de seus direitos e passar a cobrá-los. Infelizmente, nem metade das equipes promove a divulgação. As que divulgam, fazem por meio de palestras, nas quais as profissionais se apresentam para a comunidade e falam sobre o seu papel e os direitos socioassistenciais.

Conforme relatos dessas equipes, a divulgação possibilita a inserção de novas famílias que precisam ser acompanhadas, pois elas passam a buscar o serviço quando ele ainda não chegou a elas. Ademais, é uma forma de desconstruir a ideia presente em muitas comunidades de que as ações ofertadas estão associadas à "boa vontade" das profissionais ou a determinados grupos políticos como ato de favor aos pobres, e não direito.

Outra estratégia utilizada pela maioria das equipes é o contato com atores sociais locais, como lideranças comunitárias e agentes de saúde. Por haver muitas comunidades espalhadas pelo território e as equipes não conseguirem visitá-las constantemente a comunicação e o vínculo das profissionais com os usuários ficam prejudicados. Então, elas contam com essas parcerias para levar informações às famílias e para mediar os atendimentos aos usuários, já que as lideranças e os agentes comunitários de saúde são da região e conhecem de perto a população, suas vulnerabilidades e potencialidades.

O compartilhamento de informações com técnicos do PBF, profissionais da saúde e da educação é fundamental para estabelecer fluxos entre os serviços socioassistenciais e setoriais. O conhecimento que cada serviço obtém acerca dos usuários é de natureza diferente. Porém, são informações que se complementam e, ao serem compartilhadas, podem ampliar a compreensão a respeito da realidade das famílias e suscitar ações em conjunto para o atendimento efetivo de suas necessidades. Além disso, alguns profissionais estão cotidianamente nas comunidades, como é o caso dos da educação, e têm acesso aos acontecimentos que afetam as famílias no dia-a-dia. Então, é indispensável que as equipes volantes dialoguem com outros serviços, já que não acessam as áreas rurais regularmente. Mas essa troca de informações acontece de modo informal e assistemático.

As atividades descritas acima carregam o potencial de fornecer dados consistentes para elaboração de um perfil das comunidades. Contudo, elas não ocorrem de forma sequenciada e contínua, já que a presença das equipes nas comunidades não é frequente. Ainda, as profissionais não sistematizam as informações que obtêm e, quando registram, raramente recorrem a elas. Assim, a maioria das equipes permanece com 
um conhecimento superficial sobre o modo de vida das famílias que atende, e isso acaba refletindo no planejamento e resultado das demais ações.

Ao não organizarem o conhecimento que têm sobre as necessidades das comunidades, essas equipes acabam por basear o planejamento das atividades a partir das demandas que lhes parecem mais imediatas, estabelecendo as prioridades de acordo com a gravidade dos casos ou pressão de outras instâncias que fazem encaminhamentos e cobram a intervenção e resposta das profissionais.

Acontece que as demandas mais imediatas são situações de direitos violados e de risco já instaladas, de responsabilidade da proteção social especial, mas que ainda são encaminhadas aos CRAS e às equipes volantes pelos profissionais das promotorias, do Ministério Público e dos Conselhos Tutelares. Segundo as profissionais, todo e qualquer trabalho com a população rural é solicitado por essas e outras instituições, mesmo que não seja de competência das equipes volantes.

Além de muitos profissionais do Sistema de Garantia de Direitos não conhecerem bem as competências dos equipamentos da proteção social básica, na maioria dos municípios em que as equipes atuam não há serviços de média e alta complexidade para acompanhar esses casos. Por isso, as profissionais das equipes volantes acabam se encarregando de prestar essa assistência, e as ações de prevenção, ainda que aconteçam, não são priorizadas.

Diante desse cenário, em que é inexistente uma rede socioassistencial, pois nem há todos os serviços que deveriam compô-la, o trabalho se fragiliza, tornando-se muito próximo do assistencialismo, com ações que se despotencializam por serem pontuais e isoladas. Assim, a política voltada para esse público específico persiste, de fato, como uma política pobre.

Mesmo que a prevenção seja o foco das ações das equipes volantes, é preciso atentar para o fato de que, na realidade concreta, o objeto de intervenção da Assistência Social - a pobreza e suas sequelas - não se manifesta isoladamente, mas de forma extremamente complexa. Na maioria dos casos, as situações de risco já estão instaladas e são associadas a diversas causas. Isso não significa que não possa haver um trabalho preventivo, pelo contrário, mas que as ações de proteção e prevenção necessitam ocorrer simultaneamente. No entanto, quando não existem serviços da proteção social especial e da saúde para trabalhar em conjunto com as equipes volantes, elas acabam sobrecarregadas e têm de escolher os casos que serão atendidos e/ou acompanhados e quais ações poderão ou não ser desenvolvidas.

De fato, dentre as demandas que as profissionais entrevistadas disseram surgir para as equipes volantes, a maioria é de responsabilidade da proteção social especial ou da saúde. As mais citadas foram abuso sexual; diferentes formas de violência advindas do núcleo familiar (doméstica, contra criança, adolescente e idoso) e uso de substâncias psicoativas (álcool e outras drogas). Também foram citadas situações de trabalho infantil; adolescentes em cumprimento de medidas socioeducativas; fome; descumprimento de condicionalidades do PBF e acompanhamento de gestantes e de pessoas com deficiência e idosos.

É necessário frisar que essas foram as demandas identificadas e diretamente apontadas pelas equipes. Entretanto, há outras que passaram despercebidas como tais. Ao descreverem as áreas rurais em que atuam, as profissionais fizeram referência a diversas necessidades ditadas pelos próprios territórios, as quais expressam características históricas, culturais e sociais que marcam essas regiões. Ainda que elas não tenham sido indicadas pelas equipes como demandas, não podemos perdê-las de vista ao analisar as respostas que são dadas a elas.

Um exemplo interessante é a necessidade da oferta de serviços de convivência nas próprias comunidades a fim de proporcionar um espaço para promoção dos direitos sociais, fortalecimento de vínculos e, consequentemente, prevenção de situações de risco para as famílias que vivem distantes dos centros urbanos. Uma das equipes começou a ofertar o serviço de convivência numa comunidade polo após identificar a demanda de um grupo de mulheres, e passou a atingir outras famílias que vivem em comunidades vizinhas, amenizando a dificuldade de acesso dos usuários aos serviços e ampliando o alcance de sua intervenção. Apesar de o exemplo ser uma exceção, ações como essa apontam possibilidades de intervenção das equipes diante dos limites impostos por territórios de difícil acesso.

Outro exemplo das necessidades ditadas pelos territórios é a existência de populações historicamente marginalizadas e excluídas do acesso a direitos sociais: comunidade quilombola e famílias sem-terra. Por possuírem características culturais particulares, viverem em condições de pobreza extrema e em áreas rurais, tornam-se grupos prioritários das ações das equipes volantes (MDS, 2011). 
Embora as profissionais tenham ofertado serviços básicos a essas populações específicas, como o cadastramento das famílias em programas sociais, possibilitando o acesso a alguns direitos socioassistenciais, as intervenções das equipes que trabalham nessas áreas revelam a carência de ações que correspondam ao contexto e às necessidades particulares das famílias quilombolas e sem-terra.

O único exemplo de intervenção mais voltada às demandas dessas famílias foi a parceria de uma equipe, mesmo que pontual, com o Movimento dos Trabalhadores Rurais Sem Terra (MST) e o Instituto Nacional de Colonização e Reforma Agrária (Incra), para realizar um estudo e acompanhamento de famílias sem-terra que estavam acampadas, ocupando uma propriedade rural, a fim de facilitar o processo de implantação de assentamento.

Ainda que esse seja um caso isolado, a articulação com movimentos sociais e outras instituições que vão além da Assistência Social, com a finalidade de atender às necessidades específicas dessas famílias, mostra que há práticas que abrem caminho por entre os entraves de atuar em contextos rurais e as amarras do conservadorismo que acompanham a história das políticas sociais brasileiras.

Portanto, reforça-se a necessidade de as profissionais que atuam em equipes volantes ampliarem a compreensão e concepção acerca das demandas e necessidades que os territórios rurais exigem, bem como se movimentarem na busca de respostas mais adequadas a elas. Para tanto, é preciso mais do que o investimento em formação e capacitação profissional. Aliado a isso, é urgente que as profissionais abandonem as posturas que naturalizam a "questão social" e culpabilizam os pobres pela sua condição, passando a enxergar as particularidades sociais, políticas, econômicas e culturais que marcam os territórios rurais do estado.

\section{Considerações finais}

É preciso analisar o trabalho na assistência social sob dois ângulos. Numa perspectiva macroestrutural, essa política pode possibilitar uma real mudança nas condições de vida de uma grande massa da população brasileira, especialmente aquela que não tem acesso a trabalho, a condições de vida digna, que sofre mais diretamente as consequências da dinâmica da vida social que negligencia os mais pobres dentre os pobres. Pela primeira vez em sua história o SUAS representa uma política social que combina combate a pobreza, inclusão produtiva, saúde e educação como eixos principais. Mas como toda política social gestada no modo de produção capitalista ela tem limites impostos pela própria dinâmica do modo de produção. Daí sua força e protagonismo dependerão sempre de uma balança que equilibra capital e trabalho, mercado e social. Num outro campo temos os debates no campo da psicologia que vêm tentando responder às demandas cada vez mais diversificadas dos seus campos de atuação, ao mesmo tempo em que discute como fazê-lo sob o signo de um projeto ético-político. Avançar em territórios, com populações antes negligenciadas, como é o caso das equipes volantes, sem dúvida revela muito da tentativa de delimitar alga de um compromisso social. Mas o projeto ético-político não é consensual, mas parece se delinear mais claramente quando no campo das políticas sociais: um projeto pela radicalização da política social, em defesa da classe trabalhadora e pela democracia.

\section{Referências}

Andrade, M. C. (1981). A produção do espaço norte-rio-grandense. Natal: EdUFRN.

Belo, R. P. N. (2015). Atuação de psicólogos em Centros de Referência da Assistência Social na região amazônica do Marajó (Dissertação de mestrado). Recuperado de https://repositorio.ufrn.br/jspui/ handle/123456789/20703

Botarelli, A. (2008). O psicólogo nas políticas de proteção social: uma análise dos sentidos e da práxis (Tese de doutorado). Recuperado de https://tede2.pucsp.br/handle/handle/17265

Buainain, A. M., \& Junior, R. G. (2013). Desenvolvimento rural do semiárido brasileiro: transformações recentes, desafios e perspectivas. Revista Franco-Brasileira de Geografia, 19. Recuperado de https://journals.openedition.org/confins/8633?lang=pt

Couto, B. R., Yazbek, M. C., \& Raichelis, R. (2011). A Política Nacional de Assistência Social e o SUAS: apresentando e problematizando fundamentos e conceitos. In B. R. Couto, M. C. Yazbek, M. O. S. Silva, \& R. Raichelis (Orgs.), O Sistema Único de Assistência Social no Brasil: uma realidade em movimento (pp. 32-65). São Paulo: Cortez.

Dantas, C. M. B. (2013). A ação do psicólogo na assistência social: "interiorização da profissão" e combate à pobreza. (Tese de Doutorado). Recuperado de https://repositorio.ufrn.br/jspui/ handle/123456789/17400

Furtado, C. (1980). Formação econômica do Brasil (17ª ed.). São Paulo: Editora Nacional.

Instituto Nacional do Semiárido. (2012). Sinopse do censo demográfico para o semiárido brasileiro. Campina Grande: Autor.

Koga, D., \& Nakano, K. (2005). Perspectivas territoriais e regionais para políticas públicas brasileiras. In A Abong nas Conferências Criança e Adolescente - Assistência Social (pp. 68-74). São Paulo: 
Abong. Recuperado de http://www.bibliotecadigital.abong.org.br/ handle/11465/207

Macedo, J. P., Sousa, A. P., Carvalho, D. M., Magalhães, M. A., Sousa, F. M. S., \& Dimenstein, M. (2011). O psicólogo brasileiro no SUAS: quantos somos e onde estamos?. Psicologia em Estudo, 16(3), 479-489. doi: 10.1590/S1413-73722011000300015

Ministério do Desenvolvimento Social e Combate à Fome. (2009a). Tipificação nacional de serviços socioassistenciais. Brasília: Autor.

Ministério do Desenvolvimento Social e Combate à Fome. (2009b). Orientações técnicas: Centro de referência de Assistência Social - CRAS. Brasília: Autor.

Ministério do Desenvolvimento Social e Combate à Fome. (2011). Resumo executivo das orientações para execução de serviços de proteção social básica e ações por equipes volantes. Brasília: Autor.

Oliveira, I. F., Dantas, C. M. B., Solon, A. F. A. C., \& Amorim, K, M. O. (2011). A prática psicológica na proteção social básica do SUAS. Psicologia \& Sociedade, 23(num. esp.), 140-149. doi: 10.1590/ S0102-71822011000400017

Oliveira, I. M. (2005). Assistência Social pós-LOAS em Natal: a trajetória de uma política social entre o direito e a cultura do atraso (Tese de Doutorado). Recuperado de https://tede2.pucsp.br/handle/ handle/17548

Paes-Sousa, R. (2013). Plano Brasil sem miséria: incremento e mudança na política de proteção e promoção social no Brasil. IPC-IG Working Paper, 113. Brasília: International Policy Centre for Inclusive Growth.
Raichelis, R. (2011). O trabalho e os trabalhadores do SUAS: o enfrentamento necessário na Assistência Social. In Ministério do Desenvolvimento Social e Combate à Fome (Org.), Gestão do Trabalho no SUAS: uma contribuição necessária (pp. 39-64) Brasília: MDS.

Romano, A. P. H. (2009). Entre socialização da informação e organização coletiva: a dimensão socioeducativa na atuação com grupos nos CRAS em São José Do Rio Preto/SP (Dissertação de Mestrado). Recuperado de https://www.franca.unesp.br/Home/ Pos-graduacao/ServicoSocial/Dissertacoes/AnaPaulaRomano_ dissertacao.pdf

Santos, M. (2000). Território e sociedade: entrevista com Milton Santos. São Paulo: Fundação Perseu Abramo.

Senra, C. M. G., \& Guzzo, R. S. L. (2012). Assistência social e psicologia: sobre as tensões e conflitos do psicólogo no cotidiano do serviço público. Psicologia \& Sociedade, 24(2), 293-299. doi: 10.1590/ S0102-71822012000200006

Spinelli, J. A. (2010). Coronéis e oligarquias no Rio Grande do Norte: primeira república e outros estudos. Natal: EDUFRN.

Ximenes, V. M., Paula, L. R. C., \& Barros, J. P. P. (2009). Psicologia comunitária e política de assistência social: diálogos sobre atuação em comunidades. Psicologia: Ciência e Profissão, 29(4), 686-699. doi:10.1590/S1414-98932009000400004

Yamamoto, O. H., \& Oliveira, I. F. (2010). Política social e psicologia: uma trajetória de 25 anos. Psicologia: Teoria e Pesquisa, 26(num. esp.), 9-24. doi: 10.1590/S0102-37722010000500002

\footnotetext{
1. A redação sobre as profissionais no gênero feminino foi realizada pelo fato de todas as 13 entrevistadas serem mulheres.

2. Informações recuperadas de http://www.ibge.gov.br/home/
}

Marilia Noronha Costa do Nascimento, Mestre em Psicologia pela Universidade Federal do Rio Grande do Norte (UFRN), é Psicóloga do Serviço de Proteção ao Adolescente em Cumprimento de Medidas Socioeducativas em Meio Aberto da Cidade de Natal/RN (MSE). Endereço para correspondência: Rua Parque das Frutas, 135. Casa 06. Bairro Parque das Árvores. Parnamirim/RN. CEP: 59154-245. Telefone para contato: (84) 99955-6508. E-mail: noronha.lila@gmail.com

Isabel Fernandes de Oliveira, Doutora em Psicologia Clínica pela Universidade de São Paulo (USP), é Professora Associada III no Programa de Pós-Graduação em Psicologia da Universidade Federal do Rio Grande do Norte (UFRN). E-mail: fernandes.isa@gmail.com 